\title{
DESEMPREGO NO BRASIL: UMA ANÁLISE EMPÍRICA DE PREVISÃO BASEADA NA METODOLOGIA BOX-JENKINS
}

\author{
Éder de Souza Beirão* \\ Maria Elizete Gonçalves** \\ Darcy Ramos da Silva Neto****
}

Resumo: Um dos problemas sociais que mais aflige os países subdesenvolvidos é o desemprego. O caso do Brasil não é diferente, visto que este problema se agravou e muito em decorrência da crise econômica que atingiu o país. Neste sentido, o presente estudo objetiva prever a da taxa de desemprego do Brasil através de análise empírica baseada na metodologia Box-Jenkins. O mesmo possui abordagem quantitativa e descritiva, embasado em pesquisa bibliográfica e documental, tendo como fonte de dados a plataforma Bases de Datos y Publicaciones Estadísticas da Comissão Econômica para a América Latina e o Caribe (CEPALSTAT). Os resultados demonstraram que a série da taxa de desemprego trimestral do Brasil, entre 1995 e 2016 é não estacionária, ou seja, a mesma não se desenvolve no tempo aleatoriamente ao redor da média, refletindo um tipo de equilíbrio. Porém, em nível, a série apresenta tendência estocástica. A tendência das taxas de desemprego indicam queda da referida taxa, porém através da previsão realizada por meio do método utilizado, pode-se observar que ocorreu a elevação da mesma, uma vez que nos periodos posteriores ao primeiro trimestre de 2016 a taxa de desemprego se elevou. Posteriormente, foi feita uma previsão fora da série que indicou que podia ocorrer uma elevação da

\footnotetext{
* Mestre em Desenvolvimento Social pela Universidade Estadual de Montes Claros (Unimontes).

** Doutora em Demografia pelo Centro de Desenvolvimento e Planejamento Regional da Universidade Federal de Minas Gerais (Cedeplar/UFMG) e Professora do Departamento de Ciências Econômicas da Universidade Estadual de Montes Claros (Unimontes).

${ }^{* * *}$ Doutorando em Economia Aplicada pela Faculdade de Economia, Administração e Contabilidade de Ribeirão Preto da Universidade de São Paulo (FEA-RP/USP).
} 
taxa trimestral de desemprego do Brasil até o último trimestre de 2019. Conclui-se que a taxa de desemprego se elevou no país no período analisado e tende a se elevar ainda mais nos próximos trimestres.

Palavras-chave: Desemprego. Previsão. Séries Temporais. Metodologia Box-Jenkins. Brasil.

\title{
UNEMPLOYMENT IN BRAZIL: AN EMPIRICAL ANALYSIS OF FORE- CASTING BASED ON THE BOX-JENKINS METHODOLOGY
}

\begin{abstract}
One of the social problems that most afflicts underdeveloped countries is unemployment. The case of Brazil is no different, as this problem has become much worse as a result of the economic crisis that hit the country. In this sense, the present study aims to predict the unemployment rate in Brazil through an empirical analysis based on the Box-Jenkins methodology. It has a quantitative and descriptive approach, based on bibliographical and documental research, having as data source the Data Bases y Publicaciones Estadisticas platform of the Economic Commission for Latin America and the Caribbean (CEPALSTAT). The results showed that the series of the quarterly unemployment rate in Brazil, between 1995 and 2016, is non-stationary, that is, it does not randomly develop over time around the mean, reflecting a type of equilibrium. However, in terms of level, the series shows a stochastic tendency. The trend in unemployment rates indicates a drop in that rate, but through the forecast made using the method used, it can be observed that it increased, since in the periods subsequent to the first quarter of 2016 the unemployment rate increased. raised. Subsequently, an out-of-series forecast was made that indicated that there could be an increase in the quarterly unemployment rate in Brazil until the last quarter of 2019. even more in the coming quarters.
\end{abstract}

Keywords: Unemployment. Forecast. Time Series. Box-Jenkins Methodology. Brazil.

\section{DESEMPLEO EN BRASIL: ANÁLISIS DE PRONÓSTICO EMPÍRICO BA- SADO EN LA METODOLOGÍA BOX-JENKINS}

Resumen: Uno de los problemas sociales que más aflige a los países subdesarrollados es el desempleo. El caso de Brasil no es diferente, ya que este problema se ha agravado mucho más como consecuencia de la crisis económica que azotó al país. En este sentido, el presente estudio tiene como 
objetivo predecir la tasa de desempleo en Brasil a través de un análisis empírico basado en la metodología Box-Jenkins. Tiene un enfoque cuantitativo y descriptivo, basado en la investigación bibliográfica y documental, teniendo como fuente de datos la plataforma de Bases de Datos y Publicaciones Estadísticas de la Comisión Económica para América Latina y el Caribe (CEPALSTAT). Los resultados mostraron que la serie de la tasa de desempleo trimestral en Brasil, entre 1995 y 2016, es no estacionaria, es decir, no se desarrolla aleatoriamente en el tiempo alrededor de la media, lo que refleja un tipo de equilibrio. Sin embargo, en términos de nivel, la serie muestra una tendencia estocástica. La evolución de las tasas de desempleo indica una caída de dicha tasa, pero a través de la previsión realizada por el método utilizado, se puede apreciar que aumentó, ya que en los períodos posteriores al primer trimestre de 2016 la tasa de desempleo aumentó. Posteriormente, se realizó un pronóstico fuera de serie que indicaba que podría haber un aumento en la tasa de desempleo trimestral en Brasil hasta el último trimestre de 2019. aún más en los próximos trimestres.

Palabras clave: Desempleo. Pronóstico. Series de tiempo. Metodología Box-Jenkins. Brasil.

\section{Introdução}

O mundo, em especial o Brasil, vêm passando por constantes mudanças em várias áreas, em decorrência do avançar da tecnologia e principalmente do fenômeno da globalização. No contexto destas transformações, a expressão das questões sociais é inevitável. Pinheiro e Dias (2009) afirmam que atualmente, a questão social é vista como sendo "a expressão das desigualdades e lutas sociais em suas múltiplas manifestações e todos os segmentos sociais envolvidos (trabalhadores e desprotegidos) são heterogêneos". Neste sentido, as questões sociais podem ser encaradas como problemas sociais. Existem diversos problemas sociais com os quais a América Latina, sobretudo o Brasil, se defronta, como desemprego, violência, criminalidade, analfabetismo, falta de moradia, problemas no acesso aos serviços de saúde, racismo, fome.

O desemprego, mais especificamente, é um dos maiores problemas sociais enfrentados pela sociedade. Os economistas clássicos afirmam que o desemprego tem sua base no funcionamento do mercado e no desejo dos 
trabalhadores de receber salários altos. Neste sentido, o desemprego seria provocado pela utilização de uma política salarial inadequada sendo este qualificado como voluntário. Para os keynesianos, o desemprego deve-se ao nível insuficiente da demanda agregada por bens e serviços (MOCHON E TROSTER, 1994).

A preocupação com a realidade do desemprego no Brasil tem crescido, tanto por parte dos estudiosos como por parte dos trabalhadores. Trata-se de um problema social que desencadeia outros, como quadros alimentares de desnutrição, informalidade, queda da qualidade dos trabalhos, evolução da situação de pobreza, miséria e indigência, corte de investimentos, aumento da criminalidade, corte em recursos de programas sociais, estancamento da expansão da capacidade produtiva etc. (KLIKSBERG, 2001). Neste sentido, o desemprego pode expressar, ou seja, pode ser uma das principais causas da desigualdade e a exclusão (NOCCIOLI, 1999).

O desemprego está estreitamente ligado e provoca carências de todo tipo na vida cotidiana; e, muitas vezes, pode configurar a realidade do desenvolvimento e do crescimento econômico (KLIKSBERG, 2001).

Entre 1995 e 2016 o número de desempregados cresceu e diminuiu por vezes, visto que houve uma tendência de crescimento entre 1995 e 2003 , chegando a $12,9 \%$ no terceiro trimestre do ano 2003, uma tendência de queda entre 2004 e 2014, chegando a 7,2\% no último trimestre de 2014 e uma nova tendência de elevação entre 2014 e 2016, chegando a $12 \%$ no primeiro trimestre de 2016 (CEPALSAT, 2018). Neste sentido, faz-se necessário abordar a temática no Brasil, visto que o país passa por um processo de recessão econômica com altas taxas de desemprego e aumento do nível da pobreza.

Nesse contexto, o presente estudo parte do seguinte questionamento: Diante dos valores passados da taxa de desemprego, no Brasil, qual é a previsão para este indicador, para o trimestres posteriores ao primeiro trimestre de 2016 ?

$\mathrm{Na}$ busca de responder à esta questão norteadora (problema de pesquisa) foi definido o objetivo geral, que consiste em prever a taxa de desemprego do Brasil através da análise empírica baseada na metodologia Box-Jenkins. 
BEIRÃO, É. S.; GONÇALVES, M. E.; SILVA NETO, D. R. Desemprego no Brasil...

Para o desenvolvimento do trabalho ora apresentado adotou-se os seguintes procedimentos metodológicos: pesquisa, levantamento e seleção bibliográfica acerca da temática proposta; análise de dados secundários obtidos na Bases de Datos y Publicaciones Estadisticas da Comissão Econômica para a América Latina e o Caribe (CEPALSTAT); construção do banco de dados e estimação dos modelos de previsão no software Stata, versão 14. A fundamentação teórica e empírica encontram-se apoiadas nas ideias e estudos de Wasmália Bivar (1993), Carlos Henrique Leite Corseuil (1994, 1996 e 2018), Ricardo Paes de Barros, José Márcio Camargo e Rosane Mendonça (1997), José Nilson Reinert (2001), Márcio Pochmann (2015) e outros autores que contribuíram significativamente para a discussão aqui proposta.

O trabalho está dividido em seis seções, a contar desta: Introdução; Revisão de Literatura; Procedimentos Metodológicos; Análise e Discussão de Resultados; Considerações Finais; e Referências.

\section{Revisão de Literatura}

Existe uma confusão entre os conceitos dos termos trabalho e emprego. Reinert (2001) define trabalho como atividade social, preponderante ao progresso material e moral da humanidade. O trabalho é uma atividade antiga que surgiu no instante em que o homem tomou ciência de sua individualidade. É, portanto, tão antigo quanto à humanidade. Pode-se imaginar que, a partir do consciência do trabalho como atividade crucial o mesmo se tornou preponderante para a sobrevivência e progresso. O emprego, por sua vez, é visto como sendo uma consequência do capitalismo. É o elo de ligação existente entre o trabalhador e o modo de produção capitalista. O trabalhador é livre e pode escolher a organização que quer estabelecer esta relação (REINERT, 2001).

Depois de ter ficado clara a distinção entre trabalho e emprego, torna-se indispensável definir o conceito de um dos problemas sociais mais graves que ocorre no mundo, sobretudo no Brasil, o desemprego.

Para Reinert (2001), "o desemprego é caracterizado como sendo a não possibilidade do trabalho assalariado nas organizações de um modo geral”. 
Diante da importância desse problema social, é preciso verificar como ele tem se manifestado na sociedade brasileira.

O desemprego está estreitamente ligado e provoca carências de todo tipo na vida cotidiana; e, muitas vezes, configura a realidade do desenvolvimento e do crescimento econômico. Junto deste crescimento de ordem econômica emerge a necessidade do alcance do desenvolvimento social, a melhoria da equidade, o fortalecimento da democracia e preservação e equilíbrio do meio ambiente (KLIKSBERG, 2001).

O desemprego não é um problema social que surgiu recentemente no Brasil. O desemprego e o subemprego urbano são atribuídos às migrações urbanas que ocorreram de forma intensa no período do processo de industrialização do Brasil. Este processo criou uma taxa de urbanização acelerada e superior ao processo de industrialização do país (MARIM, 1976).

Além do desemprego, que traduz um problema social recorrente no Brasil e em outros países, outro termo que precisa ser evidenciado é a taxa de desemprego, a variável analisa no presente estudo. A taxa de desemprego é diferente do termo desemprego, uma vez que esta refere-se a uma medida do número de pessoas desempregadas e/ou desocupadas em uma determinada localidade. Esse indicador é utilizado em quase todos os países do mundo e aqui no Brasil é calculado pelo Instituto Brasileiro de Geografia e Estatística (IBGE). O mesmo é adquirido estatisticamente com o total de pessoas que buscam emprego numa determinada localidade com relação à População Economicamente Ativa (PEA).

A PEA diz respeito à população que têm idade para trabalhar, tanto a população desempregada ou desocupada, quanto sua contraparte, formada pela população ocupada. Fazem parte da PEA as pessoas que têm idade para trabalhar (16 anos ou mais) e que estão trabalhando ou procurando trabalho (ocupadas e desocupadas). Outro termo importante a ser retratado que tem relação com a PEA é População em Idade Ativa (PIA). A PIA é formada pela soma das PEA e das Pessoas Não-economicamente Ativas (PNEA).

As taxas de desemprego são elevadas e o problema social tem sido difundido com mais intensidade no mundo, na América Latina e sobretudo na sociedade brasileira. Trata-se de um tema que tem sido levado ao conhecimento de todos por meio da divulgação de bases de dados disponibi- 
lizadas em plataformas de institutos de pesquisa brasileiros como é o caso do IBGE, Instituto de Pesquisa Econômica Aplicada (Ipea), Departamento Intersindical de Estatística e Estudos Socioeconômicos (DIEESE) e os internacionais, como por exemplo o CEPALSTAT etc.

A globalização e os avanços da tecnologia tem trazido à tona o efeito negativo do desemprego, o chamado desemprego estrutural, que ameaça à paz social de toda a humanidade, sobretudo do Brasil. O processo de globalização é a realidade social, econômica, política e cultural de âmbito transnacional que modifica o lugar e seu respectivo significado, pois "tudo que é local, nacional e regional recebe o impacto da transnacionalização”. A globalização desenvolveu uma sociedade global e criou um cenário problemático e contraditório (IANNI, 1997).

Nesse processo, as máquinas e equipamentos estão cada vez mais independentes do ser humano, pois, segundo Sena (1999, p.103), "a produção que necessitava de milhares de pessoas, hoje se realiza com centenas, quiçá dezenas de trabalhadores". De acordo com o autor, "desesperados, os desempregados são facilmente captados pelos setores que oferecem oportunidade de sobrevivência: terrorismo, crime organizado, tráfico de drogas, guerrilhas etc".

Sena (1999, p.104) afirma que a predominância do mercado no mundo, coloca o lucro acima de tudo. Num futuro próximo, esta relação levará ao aumento da produção, redução do preço e inexistência do consumidor por falta de emprego. Neste sentido, é possivel constatar que o desemprego é um problema social que tem criado outros problemas no Brasil, como corte de investimentos, aumento da miséria, das estatísticas da pobreza e criminalidade, corte em recursos de programas sociais, estancamento da expansão da capacidade produtiva.

Sendo assim, faz-se necessário o estudo do desemprego, sobretudo, pelo fato de que para Becker (2010, p.44), "o estudo da taxa de desemprego é muito útil na tomada de decisão de políticas públicas em relação ao mercado de trabalho. Através desses dados podem ser definidos incentivos fiscais, análise de dados referentes à previdência, análises setoriais e de renda." 


\subsection{Evidências Empiricas}

Os estudos sobre a temática do desemprego são organizados em três grupos. O primeiro destes ocupa-se de aprimorar o conceito de desemprego e especificar como este pode ser operacionalizado. O segundo visava analisar o comportamento da taxa de desemprego, avaliar seus determinantes, identificar sua propriedade ou identificar como este indicador se relaciona com outras Variáveis socioeconómicas. Já o terceiro grupo, é aquele que se ocupa de analisar a composição e estrutura do desemprego (BARROS, CAMARGO E MENDONÇA, 1997). O estudo em questão enquadra-se no segundo tipo de estudo, pois objetiva analisar o comportamento da taxa de desemprego do Brasil e pretende com isso fazer uma previsão deste indicador à médio prazo.

Inicialmente, no Brasil, poucas análises foram realizadas acerca do desemprego no Brasil. Estas focaram seus esforços em analisar a estrutura do desemprego no país como foi o caso dos estudos de Bivar (1993), Ferreira (1993), Rocha (1993), Corseuil (1994) e Corseuil, Reis e Urani (1996). Apesar deste fato, o que se tem observado é que predominantemente os estudos sobre o desemprego versam sobre sua evolução.

O que pode ser observado é que nos últimos anos, o Brasil têm enfrentado uma tendência de crescimento de sua taxa de desemprego. Esta tendência pode ter sido causada pela discrepância existente entre a evolução da demanda e da oferta de trabalhadores disponivel no mercado de trabalho. Essa desconformidade expressa o crescimento recente da taxa de desemprego no Brasil, cuja motivação principal encontra-se associada à recessão na economia nacional. A partir do ano 2015 houve uma queda no nivel de atividade que veio acompanhada da redução da quantidade de ocupado e do rendimento médio recebido pelos trabalhadores (POCHMANN, 2015).

Esta elevação, consequentemente, provoca o acirramento no mercado de trabalho entre os trabalhadores que perderam o emprego e os novos ingressantes do mercado de trabalho, os jovens. Por este e outros motivos o desemprego não é homogéneo entre os trabalhadores (POCHMANN, 2015). $\mathrm{O}$ fato dos jovens estarem ingressando no mercado de trabalho pode estar causando a piora na renda dos adultos dentro deste contexto recessivo que defronta o Brasil (CORSEUIL, POLOPONSKY E FRANCA, 2018). 
BEIRÃO, É. S.; GONÇALVES, M. E.; SILVA NETO, D. R. Desemprego no Brasil...

A preocupação com a elevação da taxa de desemprego no Brasil não se limita ao número de pessoas desempregadas. O problema da desocupação torna-se mais alarmante quando esta taxa é observada de forma desagregada. Quanto menor for a qualificação maiores serão as taxas de desemprego do que quando há maior qualificação profissional; a taxa entre os jovens é maior que os adultos; as mulheres e os filhos, na condição dependentes da renda de um determinado grupo familiar, são os mais atingidos pelo desemprego tanto nacional quanto internacionalmente, como pode ser evidenciado pelos estudos de Wood (1995), Maia (2001), Layard, Nickell e Jackman (2009), Costa (2015), Pochmann (2015) e Ferreira (2016).

O desemprego e as características individuais dos trabalhadores já foram alvo de diversos estudos, tanto em nivel nacional quanto internacional. Internacionalmente, dentre os vários estudos que abordaram a questão do desemprego, suas características e composição, destacam-se aqueles desenvolvidos por Blanchard (2005), Layard, Nickell e Jackman (2009) e Biavaschi et al. (2012).

Blanchard (2005) estudou o desemprego nos países da Europa e nos Estados Unidos da América (EUA). O autor constatou que em todos os países analisados, o aumento da taxa de desemprego está associada ao fato do jovens não serem qualificados o suficiente para adentrarem no mercado de trabalho. Os autores ainda chegaram à conclusão de que países como Itália e Grécia possuem taxas de desemprego juvenil muito mais altas que as demais nações analisadas. A Alemanha, por sua vez, o menor índice de desocupados juvenis e isto se deve aos programas de treinamento desenvolvidos no país.

Em seu estudo, Layard, Nickell e Jackman (2009) mensuraram as diferenças existentes nas taxas de desemprego de diversos grupos. Os grupos levaram em consideração alguns critérios como idade, qualificação da mão de obra, raça, região e sexo. Assim como o estudo anterior, os autores analisaram os países do continente europeu e os EUA. Estes chegaram à conclusão de que trabalhadores semiqualificados e qualificados obtiveram uma taxa de desemprego 4 vezes maior que a dos profissionais com maior qualificação e que assumem cargos de gerência.

Biavaschi et al. (2012) desenvolveu um estudo que objetivava investigar os determinantes das altas taxas de desemprego juvenil em países desenvolvidos e em nações em desenvolvimento com ênfase na formação profissional 
e nas políticas educacionais adotadas pelos governos destes estados-nação. Os autores chegaram à conclusão que fatores demográficos, o crescimento econômico e as instituições integrantes do mercado de trabalho são preponderantes para explicar a transição dos jovens para o trabalho. Para Biavaschi et al. (2012) que a educação e a formação profissional são fatores de suma importância para a inserção do jovem no mercado de trabalho.

Nacionalmente, alguns estudos também se destacam ao abordar a questão do desemprego, de sua composição e especificação de suas características. Nacionalmente, dentre os vários estudos que abordaram a questão do desemprego, suas características e composição, destacam-se aqueles desenvolvidos por Bivar (1993), Corseuil (1994), Corseuil, Reis e Urani (1996), Barros, Camargo e Mendonça (1997), Flori (2003), Pochmann (2015) e Ferreira (2016).

Bivar (1993) em seu estudo analisou a composição do desemprego no Brasil, por sexo e duração, no período de 1983 a 1990 com dados da Pesquisa Mensal de Emprego (PME). Através dos resultados da pesquisa a autora chegou à conclusão que a duração do desemprego variava entre 1,5 e 6 meses e que as mulheres detinham a maior probabilidade de ficarem desempregadas enquanto os homens possuíam uma maior probabilidade de inserção no mercado de trabalho.

Corseuil (1994), por sua vez, desenvolveu um estudo em que analisou o desemprego no Brasil metropolitano em meados da década de 1980, utilizando dados da Pesquisa Nacional por Amostra de Domicílios (PNAD). O autor chegou à conclusão que o desemprego ficou bem distribuído entre os grupos da PEA e recebeu maior destaque entre os jovens e indivíduos com nível intermediário de educação. O desemprego nesta década foi fortemente influenciado pelos ciclos econômicos.

Corseuil, Reis e Urani (1996) estudaram os determinantes da composição da taxa de desemprego do Brasil metropolitano no período de 1986 a 1995 com dados da PME. Os autores analisaram a evolução, incidência e composição do desemprego levando em consideração aspectos como o faixa etária, gênero, grau de escolaridade, posição na família e região metropolitana e chegaram à conclusão que este incide mais sobre homens, jovens, com posição de filhos no grupo familiar, que possuem grau de escolaridade mediano e habitante de municípios pertencentes a regiões metropolitanas dos estados da região Nordeste do país. 
BEIRÃO, É. S.; GONÇALVES, M. E.; SILVA NETO, D. R. Desemprego no Brasil...

Barros, Camargo e Mendonça (1997) em seu estudo, analisaram a estrutura (composição) do desemprego no Brasil no período de 1982 a 1993 nas regiões metropolitanas brasileiras, utilizando-se de dados da PME. Os mesmos utilizaram como critérios a idade, nível de instrução, posição do domicílio, posição na ocupação, setor de atividade e sexo. Por meio dos resultados encontrados foi possivel concluir que o desemprego no período analisado foi maior entre os jovens, filhos, mulheres, cônjuges, trabalhadores informais e entre aqueles que trabalham com educação mediana.

Flori (2003) analisou a composição do desemprego juvenil (população que se enquadra na faixa etária entre 14 e 24 anos) no Brasil, no período de 1983 a 2002 através da utilização de dados da PME. Os resultados apontaram para algumas evidencias, como o fato da duração do desemprego do jovens e dos mais velhos ser muito semelhante. A taxa de inserção no mercado de trabalho juvenil foi maior que a de outras faixas etárias. $\mathrm{O}$ número de jovens sem experiência profissional é menor que o de pessoas dessa faixa etária que já possuem algum tipo de experiência comprovada.

Em seu estudo, Pochmann (2015), analisou a evolução do desemprego no início do ano 2015 nas regiões metropolitanas brasileiras por meio da utilização de dados da PME. Os resultados encontrados indicaram que o crescimento da taxa de desemprego mensal deu-se de forma heterogênea entre as regiões metropolitanas estudadas.

Já Ferreira (2016), analisou a taxa de desemprego e a inatividade no âmbito das regiões metropolitanas do Brasil, utilizando como critérios a cor/raça, escolaridade, faixa etária e gênero no ano de 2014, com dados da PNAD e utilizando a metodologia do Modelo Logit Multinominal. Em relação ao gênero e a faixa etária, os resultados mostraram que as probabilidades do desemprego e inatividade foram maiores entre mulheres e jovens de 10 a 17 anos de idade. Com relação a escolaridade, quanto maior o número de anos de estudo menor a inatividade. Outra conclusão foi que indivíduos com cerca de 9 anos de escolaridade possuem maior probabilidade de desemprego. No que diz respeito à cor, pessoa de cor preta apresentaram menores probabilidades de inatividade e maiores de desemprego. As taxas mais significativas de desemprego ocorreram nas regiões metropolitanas das regiões Norte e Nordeste do Brasil.

Diferente dos estudos aqui apresentados, o presente trabalho visa prever a taxa de desemprego do Brasil através da análise empírica baseada 
na metodologia Box-Jenkins e não analisar estrutura do desemprego. Semelhante a estes, o estudo evidenciará a evolução da taxa de desemprego no período de 1995 a 2016, período em que o Brasil foi governado por quatro presidentes diferentes (Fernando Henrique Cardoso, Luís Inácio Lula da Silva, Dilma Rouseff e Michel Temer) que adotaram políticas económicas e sociais distintas e passaram por ciclos econômicos diferentes que impactaram a economia de formas diversas provocando assim a elevação ou redução da taxa de desemprego no país. Neste mesmo período, o mercado de trabalho e o próprio desemprego passou por intensas modificações em sua composição (estrutura) e evolução, porém o trabalho não versará sobre tais modificações, pois não é o propósito do mesmo.

\section{Metodologia}

Com o intuito de atender ao objetivo traçado para este estudo, foi realizada uma pesquisa de abordagem quantitativa. Quanto aos objetivos, a pesquisa se classifica em descritiva. Quanto aos procedimentos técnicos, a pesquisa se classifica em documental. A variável analisada foi a taxa de desemprego trimestral (desemp $p_{t}$ do Brasil, disponibilizada na plataforma CEPALSTAT. O período analisado compreende desde o primeiro trimestre de 1995 até o primeiro trimestre do ano de 2016, compreendendo um corte temporal de 22 anos equivalente a 85 trimestres. A escolha do período foi motivada pela disponibilidade de dados na plataforma CEPALSTAT, uma vez que os dados do mercado de trabalho do Brasil não foram atualizados na mesma desde o ano 2016. A previsão foi feita para 14 trimestres a frente. Para realizar a análise de previsão em séries temporais foi utilizado a metodologia de Box-Jenkins.

\subsection{Procedimentos Econométricos}

Para a previsão do desemprego no Brasil, foi realizada uma análise empírica com o conjunto de dados de series temporais da taxa trimestral do desemprego (percentual de desocupados).

Inicialmente foram realizados testes que buscaram verificar se os dados da série analisada são estacionários ou não estacionários. De acordo 
BEIRÃO, É. S.; GONÇALVES, M. E.; SILVA NETO, D. R. Desemprego no Brasil...

com Bueno (2012), “o conceito de estacionaridade é a principal ideia que se deve ter para estimar uma série temporal". Ainda de acordo com autor, a constatação da estacionaridade permite proceder com inferências estatísticas sobre os parâmetros estimados com base na realização de um processo estocástico.

Neste sentido, o teste de raiz unitária foi utilizado para verificar a estacionariedade (ou não estacionariedade) da série. Entre os testes disponiveis, destaca se o teste de Dickey e Fuller, que permite verificar se a série possui ou não raiz unitária. O mesmo foi sugerido pelos estudos de David A. Dickey e Wayne Arthur Fuller ${ }^{1}$, no ano de 1979.

O teste Dickey-Fuller (DF) também pode ser conhecido como estatística ou teste de tau ( $(\tau)$. Conforme Gujarati e Porter (2011, p.749), se a hipótese de que $\delta=0$ for rejeitada (a série temporal é estacionária), poderemos utilizar o costumeiro teste $\mathrm{t}$ (Student). Os autores argumentam que o teste é unilateral porque a hipótese alternativa é que $\delta<0$ (ou $\rho<1)$.

Apesar do teste de Dickey-Fuller ser bem difundido entre seus usuários, o mesmo também possui limitações. Conforme Pindyck e Rubinfeld (2004), "seu poder é bastante limitado, pois permite apenas rejeitar (ou deixar de aceitar) a hipótese de que a série não é um passeio aleatório. A impossibilidade de rejeição (a um nivel de significância elevado) oferece apenas uma evidência tênue em favor da hipótese de passeio aleatório".

Neste sentido foi desenvolvido o teste de Dickey-Fuller Aumentado (DFA ou ADF), adequando, segundo Gujarati e Porter (2011, p.751), quando os termos de erro $\left(u_{t}\right)$ autocorrelacionados são adicionados os valores defasados da variável dependente $\Delta Y_{t}$.

Depois da etapa de identificação da estacionariedade da série temporal utilizada no estudo, o próximo passo é realizar sua previsão. A previsão é de suma importância para a análise econométrica. A previsão pode ser feita por meio de vários métodos, porém os dois principais e/ou mais populares são o de processo autoregressivo integrado de média móvel (ARIMA), popularmente conhecido como metodologia de Box-Jenkins ${ }^{2}$ e o método de vetores autoregressivos (VAR).

\footnotetext{
${ }^{1}$ DICKEY, D. A.; FULLER, W. A. Distribution of the estimators for autoregressive time series with a unit root. Journal of the Statistical Association, v.74, p. 427-431, 1979.

${ }^{2}$ BOX, G. P. E.; JENKINS, G. M. Times series analysis: forecasting and control. ed. rev. Holden Day, São Francisco: Holden, 1978.
} 
Os estudos de George Box e Gwilym Jenkins conduziram a uma nova geração de ferramentas construídas com o objetivo de realizar previsões.

Sobre a metodologia Box-Jenkins, Gujarati e Porter (2011, p.768) afirmam que "a ênfase desses métodos não está na construção dos métodos uniequacionais ou de equações simultâneas, mas na análise probabilística, ou estocástica, das propriedades da própria serie temporal econômica sob a filosofia deixe os dados falarem por si mesmo".

Os autores completam apontando para o fato dos "modelos de séries temporais do tipo BJ permitem que $Y_{t}$ seja explicado pelos valores passados, ou defasados, do próprio $Y$ e dos temos de erro estocástico".

A Equação (1) apresenta a especificação da metodologia de Box-Jenkins para a variável em estudo:

$$
\operatorname{desemp}_{\mathbf{t}}=\beta_{0}+\beta_{1} \operatorname{desemp}_{\mathrm{t}-1}+\mu_{\mathrm{t}}
$$

Onde desemp $p_{t}$ é a variável dependente; $\beta_{0}$ e $\beta_{1}$ são os parâmetros a serem estimados; desemp $p_{t-1}$ é variável explicativa no momento t-1 e $\mu_{\mathrm{t}}$ representa o termo de erro.

\section{Resultados e Discussão}

O Brasil têm experimentando uma elevação em suas taxas de desemprego. A evolução do desemprego no Brasil pode ser observada por meio de dados referentes ao percentual de pessoas desempregadas, no período de 1995 a 2016, apresentados no Quadro 1. 
BEIRÃO, É. S.; GONÇALVES, M. E.; SILVA NETO, D. R. Desemprego no Brasil...

Quadro 1 - Taxa de desemprego trimestral do Brasil entre 1995 a 2016

\begin{tabular}{l|r|r|r|r}
\hline Ano & $\mathbf{1}^{\mathbf{0}}$ Trimestre & $\mathbf{2}^{\mathbf{0}}$ Trimestre & $\mathbf{3}^{\mathbf{0}}$ Trimestre & $\mathbf{4}^{\mathbf{0}}$ Trimestre \\
\hline 1995 & $4.4 \%$ & $4.5 \%$ & $5.0 \%$ & $4.8 \%$ \\
1996 & $5.8 \%$ & $6.0 \%$ & $5.5 \%$ & $4.5 \%$ \\
1997 & $5.6 \%$ & $6.0 \%$ & $5.9 \%$ & $5.3 \%$ \\
1998 & $7.6 \%$ & $8.0 \%$ & $7.8 \%$ & $6.9 \%$ \\
1999 & $7.8 \%$ & $7.9 \%$ & $7.5 \%$ & $7.0 \%$ \\
2000 & $8.0 \%$ & $7.7 \%$ & $7.0 \%$ & $5.9 \%$ \\
2001 & $6.0 \%$ & $6.6 \%$ & $6.2 \%$ & $6.2 \%$ \\
2002 & $12.2 \%$ & $12.0 \%$ & $11.7 \%$ & $10.8 \%$ \\
2003 & $11.6 \%$ & $12.7 \%$ & $12.9 \%$ & $12.0 \%$ \\
2004 & $12.2 \%$ & $12.3 \%$ & $11.2 \%$ & $10.2 \%$ \\
2005 & $10.5 \%$ & $10.1 \%$ & $9.5 \%$ & $9.2 \%$ \\
2006 & $9.9 \%$ & $10.3 \%$ & $10.4 \%$ & $9.2 \%$ \\
2007 & $9.8 \%$ & $10.0 \%$ & $9.3 \%$ & $8.1 \%$ \\
2008 & $8.4 \%$ & $8.1 \%$ & $7.8 \%$ & $7.3 \%$ \\
2009 & $8.6 \%$ & $8.6 \%$ & $7.9 \%$ & $7.2 \%$ \\
2010 & $7.4 \%$ & $7.3 \%$ & $6.6 \%$ & $5.7 \%$ \\
2011 & $6.3 \%$ & $6.3 \%$ & $6.0 \%$ & $5.2 \%$ \\
2012 & $8.6 \%$ & $8.5 \%$ & $7.6 \%$ \\
2013 & $8.6 \%$ & $8.5 \%$ & $7.2 \%$ \\
2014 & $8.0 \%$ & $8.2 \%$ & $7.8 \%$ & $7.2 \%$ \\
2015 & $8.7 \%$ & $8.0 \%$ & $9.7 \%$ & $9.8 \%$ \\
2016 & $12.0 \%$ & $9.1 \%$ & - & - \\
\hline
\end{tabular}

Fonte: Elaborado pelos autores.

O Quadro 1 apresentou a evolução da taxa de desemprego no Brasil trimestral no Brasil entre 1995 e 2016. A média da taxa de desemprego trimestral no Brasil no período que compreende o $1^{\circ}$ trimestre de $1995 \mathrm{e}$ o $1^{\circ}$ trimestre de 2016 é de $8.18 \%$, sendo que a taxa mínima ocorreu no primeiro trimestre de 1995 (4,4\%) e a máxima no terceiro trimestre do ano de 2003. A taca que mais se repetiu (moda) foi de $6 \%$ e a mediana é equivalente a $7,97 \%$. O Gráfico 01 faz a representação gráfica da série, em nível. 
Gráfico 1 - Taxa de desemprego trimestral do Brasil entre 1995 e 2016

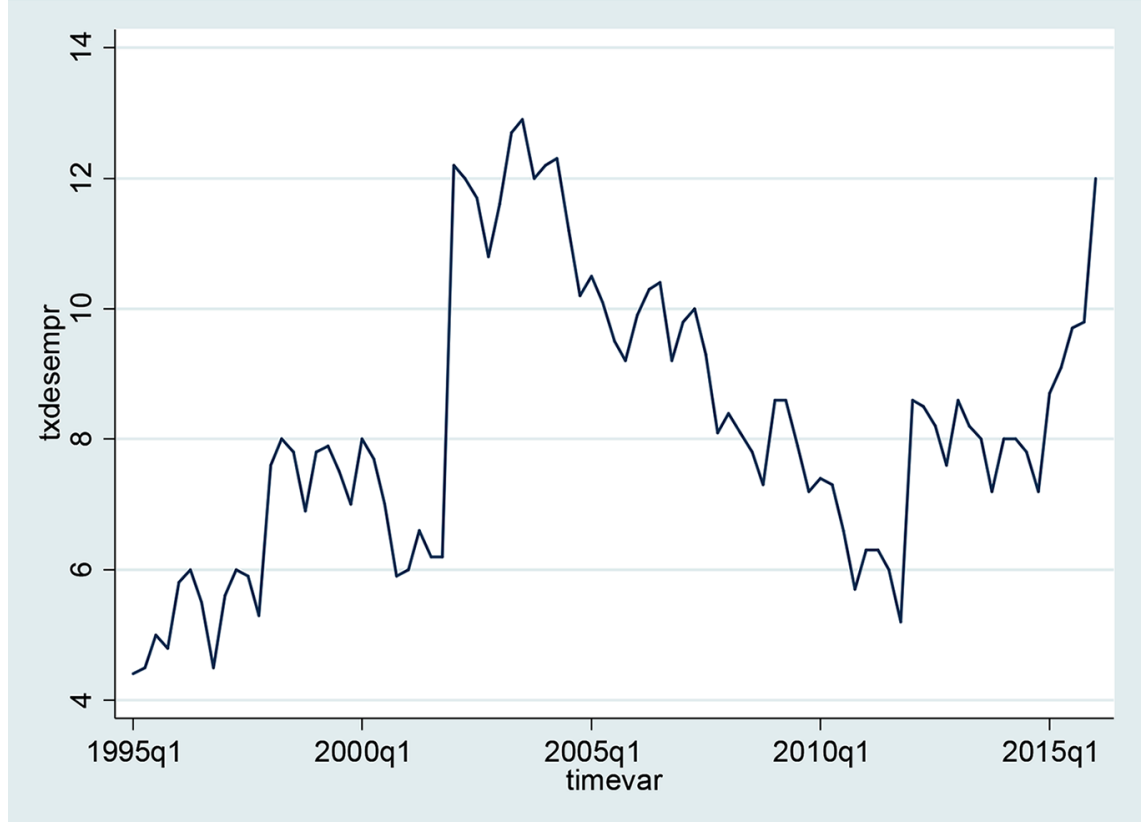

Fonte: Elaborado pelos autores com base nos dados do CEPALSTAT (2018).

A representação gráfica em nível da taxa de desemprego trimestral do Brasil entre os anos de 1995 e 2016 não sugere se a série é estacionária ou não. Neste sentido, faz-se necessário realizar um teste simples realizado para testar a estacionariedade da série temporal. O teste referido é o da função de autocorrelação (FAC). Esta função gerou um correlograma da taxa de desemprego trimestral do Brasil entre 1995 e 2016, que é apresentado na Tabela 1. 
BEIRÃO, É. S.; GONÇALVES, M. E.; SILVA NETO, D. R. Desemprego no Brasil...

Tabela 1 - Correlograma amostral da taxa de desemprego trimestral do Brasil entre 1995 e 2016

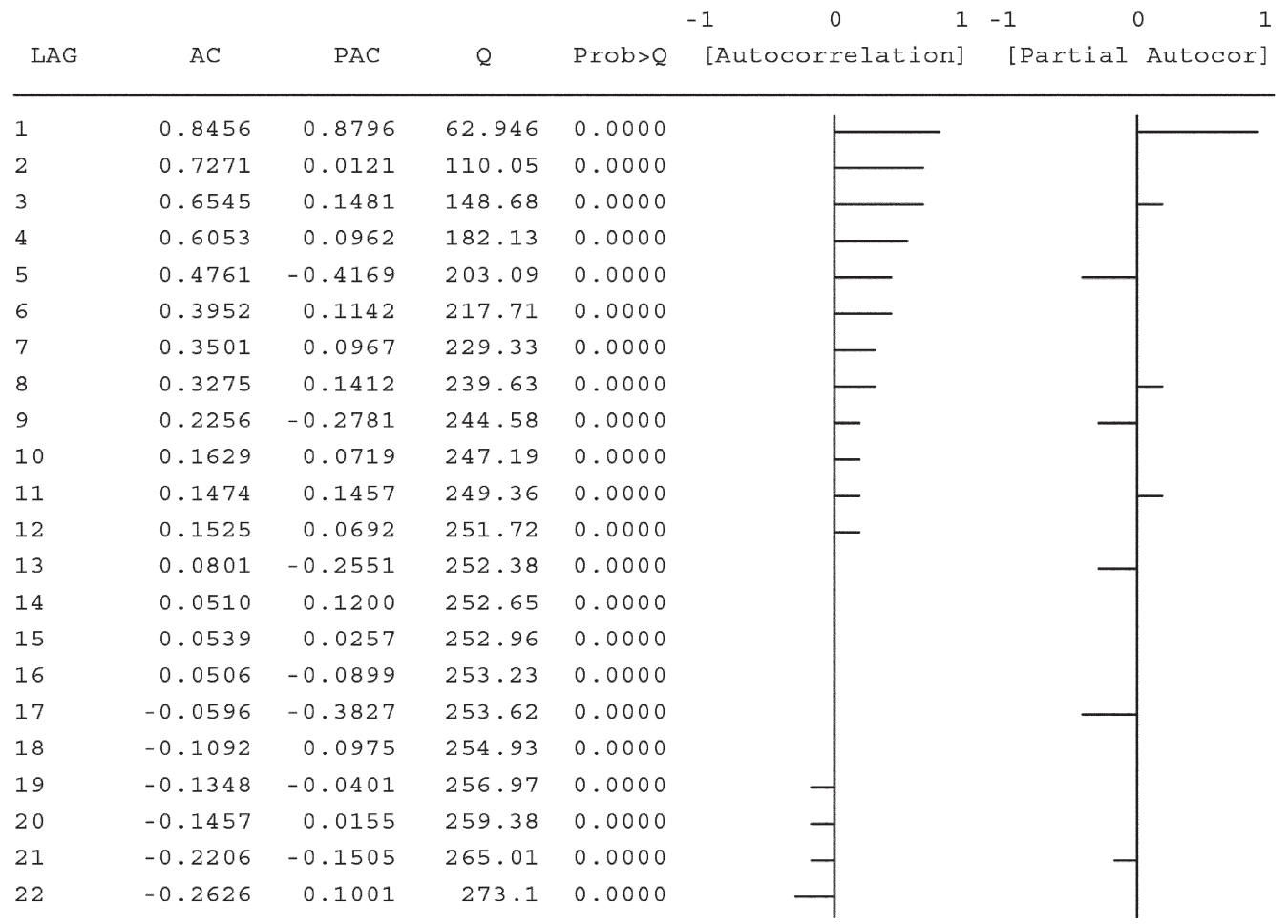

Fonte: Elaborada pelos autores com base nos dados do CEPALSTAT (2018).

O correlograma em questão apresenta 22 defasagens (LAGs). Observa-se que o mesmo apresenta coeficiente de autocorrelação com valor muito alto na defasagem $1(0,8456)$ e diminui lentamente, indicando a não estacionariedade da série temporal.

Neste correlograma foi limitada a extensão das defasagens apresentadas. A série apresenta 85 observações e o software estatístico apresentou o resultado para 22 defasagens.

Voltando a questão da estacionariedade do conjunto de dados, o correlograma sugerem a não estacionaridade. Para comprovar tal indício, faz-se necessário a realização de testes específicos.

Portanto, é indispensável a utilização do teste de raiz unitária, neste caso, o teste de Dickey-Fuller (DF); que considera como hipótese nula a presença de raiz unitária. O Gráfico 2 apresenta a primeira diferença da taxa de desemprego trimestral do Brasil entre 1995 e 2016. 


\section{Gráfico 2 - Taxa de desemprego trimestral do Brasil entre 1995 e 2016, em pri- meira diferença}

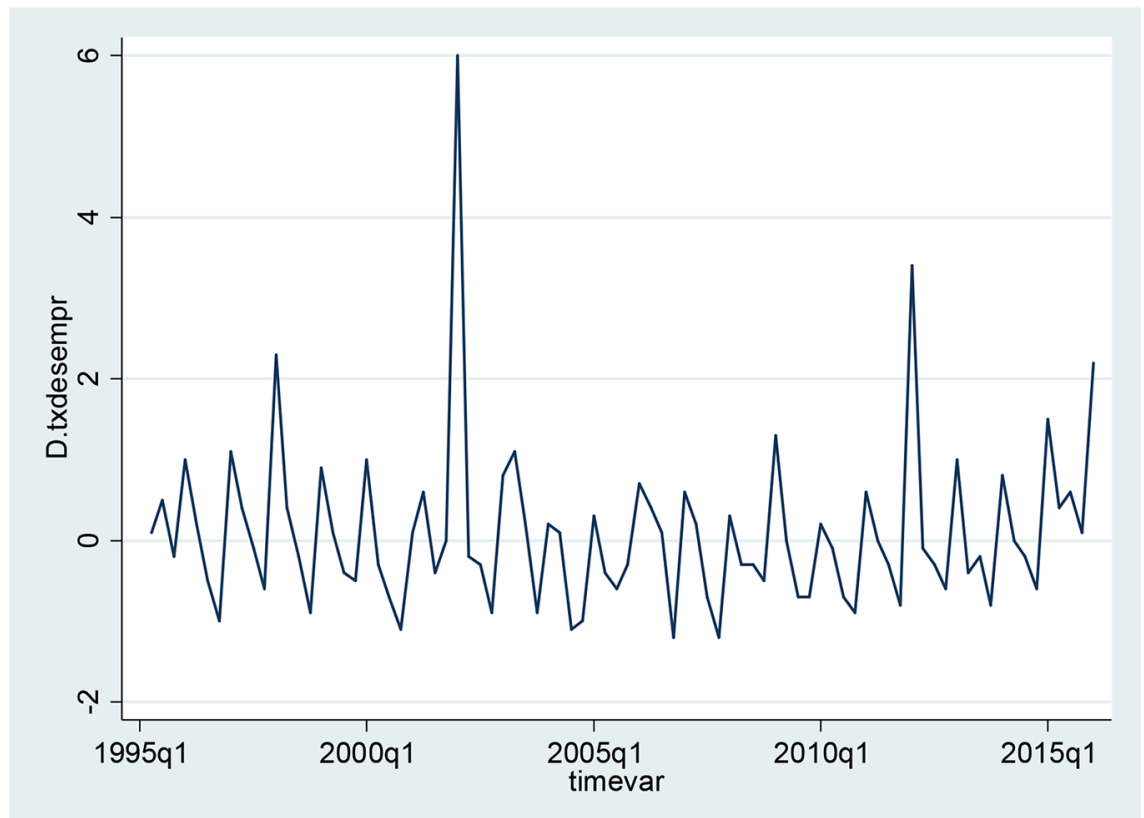

Fonte: Elaborado pelos autores com base nos dados do CEPALSTAT (2018).

A representação gráfica com a primeira diferença da taxa de desemprego trimestral do Brasil entre os anos de 1995 e 2016 sugere que a mesma é estacionária. Para comprovar a estacionariedade foi realizado o teste de raiz unitária (proposto por Dickey-Fuller), onde o $p$-valor apresentado foi de 0,00 , abaixo de $5 \%$. Neste caso, a hipótese nula $\left(\mathrm{H}_{0}\right)$ foi rejeitada e conclui-se que a série em primeira diferença é estacionária.

Comprovada a estacionariedade da série, partir-se-á para a estimação do modelo ARIMA ou aplicação da metodologia Box-Jenkins. Antes, porém, foram realizados exercícios buscando a ordem $\mathrm{AR}(\mathrm{p})$ e MA(q) do modelo.

De acordo com Gouveia e Monsueto (2016), para buscar a ordem $p$ de um processo autoregressivo (AR), analisa se o gráfico da função autocorrelação parcial (FACP). Os Gráfico 3 e 4 apresentam a FACP e a FAC, em primeira diferença da taxa de desemprego trimestral do Brasil entre 1995 e 2016, respectivamente 
BEIRÃO, É. S.; GONÇALVES, M. E.; SILVA NETO, D. R. Desemprego no Brasil...

\section{Gráfico 3 e 4 - Autocorrelação parcial e simples, em primeira diferença da taxa de desemprego trimestral do Brasil entre 1995 e 2016}
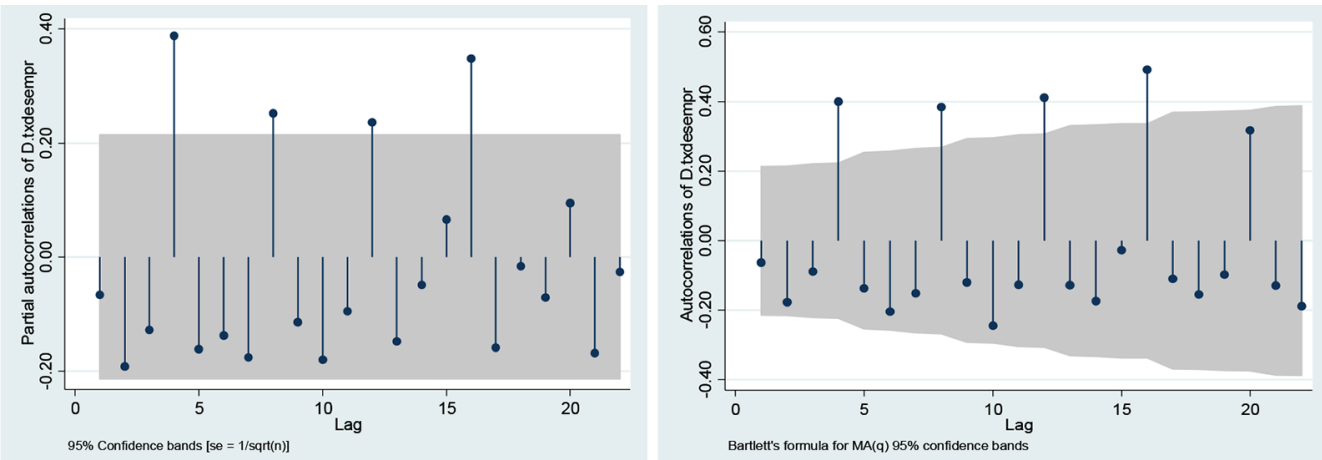

Fonte: Elaborado pelos autores com base nos dados do CEPALSTAT (2018).

O primeiro gráfico demonstra a sazonalidade da série estudada, em decorrência da existência de picos significativos de 4 em 4 semestres. $O$ mesmo ocorre com o segundo, possibilitando que possamos concluir que a série em estudo é sazonal, devida a existência de picos de 4 em 4 trimestres.

Tendo identificado a estacionariedade do conjunto de dados e feito a análise das funções de autocorrelação parcial e simples em primeira diferença da taxa de desemprego trimestral do Brasil entre 1995 e 2016, partimos para a estimação do processo ARIMA (ARMA). A estimação do modelo SARIMA (ARMA4) se justifica pelo fato do conjunto de dados ser sazonal. O processo foi estimado em 4 modelos. A Tabela 2 apresenta a descrição dos modelos.

Tabela 2 - Descrição dos modelos

\begin{tabular}{l|c|c}
\hline Modelo & ARIMA & SARIMA \\
\hline Modelo1 & ARMA $(1,1,0)$ & ARMA4 $(1,1,0,4)$ \\
Modelo2 & ARMA $(0,0,1)$ & ARMA4 $(1,1,0,4)$ \\
Modelo3 & ARMA $(1,0,0)$ & ARMA4 $(1,1,0,4)$ \\
Modelo4 & ARMA $(1,0,1)$ & ARMA4 $(1,1,0,4)$ \\
\hline
\end{tabular}

Fonte: Elaborada pelos autores com base nos dados do CEPALSTAT (2018).

Em todos os modelos estimados, a variável encontra-se em primeira diferença. A Tabela 3 apresenta a estimação dos modelos ARIMA/SARIMA. 
Tabela 3 - Estimação dos modelos ARIMA/SARIMA

\begin{tabular}{|c|c|c|c|c|c|}
\hline Modelo & ARMA & Coeficiente & Erro & Teste $z$ & $\mathbf{P}>|\mathbf{z}|$ \\
\hline ARMA $(1,1,0)$ & ar L1. & -0.4666248 & 0.057123 & -8.17 & 0.00 \\
\hline $\operatorname{ARMA} 4(1,1,0,4)$ & ar L1. & -0.518865 & 0.0542237 & -9.57 & 0.00 \\
\hline $\begin{array}{l}\operatorname{ARMA}(0,0,1) \\
\operatorname{ARMA} 4(1,1,0,4)\end{array}$ & $\begin{array}{r}\operatorname{ma} \mathrm{L} 1 . \\
\text { ar L1. }\end{array}$ & $\begin{array}{r}0.1171448 \\
-0.4912576\end{array}$ & $\begin{array}{l}0.1430718 \\
0.0433276\end{array}$ & $\begin{array}{r}0.82 \\
-11.34\end{array}$ & $\begin{array}{r}0.413 \\
0.00\end{array}$ \\
\hline $\begin{array}{l}\operatorname{ARMA}(1,0,0) \\
\operatorname{ARMA} 4(1,1,0,4)\end{array}$ & $\begin{array}{l}\text { ar L1. } \\
\text { ar L1. }\end{array}$ & $\begin{array}{r}0.128123 \\
-0.4925586\end{array}$ & $\begin{array}{r}0.13256 \\
0.0433048\end{array}$ & $\begin{array}{r}0.97 \\
-11.37\end{array}$ & $\begin{array}{r}0.334 \\
0.00\end{array}$ \\
\hline $\operatorname{ARMA}(1,0,1)$ & ar L1. & -0.7589535 & 0.0977521 & -7.76 & 0.000 \\
\hline ARMA4 $(1,1,0,4)$ & $\begin{array}{r}\operatorname{ma} \mathrm{L} 1 \text {. } \\
\operatorname{ar} \mathrm{L} 1 .\end{array}$ & $\begin{array}{r}0.9999925 \\
-0.4540048\end{array}$ & $\begin{array}{r}325.0132 \\
0.0583011\end{array}$ & $\begin{array}{r}0.00 \\
-7.79\end{array}$ & $\begin{array}{l}0.998 \\
0.000\end{array}$ \\
\hline
\end{tabular}

Fonte: Elaborado pelos autores com base nos dados do CEPALSTAT (2018).

Através da análise da Tabela anterior é possivel inferir que o Mode104 ou ARMA $(1,0,1)$ / ARMA4 $(1,1,0,4)$ apresentou resultados estatisticamente significativos em detrimento do Modelo1, Modelo2 e Modelo3, indicando que este é o melhor modelo. Para confirmar tal escolha, faz-se necessário a realização do teste Akaike. A Tabela 4 apresenta a estimação do teste Akaike.

Tabela 4 - Estimação dos modelos ARIMA/SARIMA

\begin{tabular}{lrr|r|r|r|r}
\hline Modelo & Observações & 11 (model) & LAGs & AIC & \multicolumn{1}{c}{ BIC } \\
\hline Modelo1 & 79 & -123.0308 & 3 & 252.0616 & 259.1699 \\
Modelo2 & 80 & -111.4114 & 3 & 228.8229 & 235.969 \\
Modelo3 & 80 & -111.3485 & 3 & 228.6969 & 235.843 \\
Modelo4 & 80 & -108.1122 & 4 & 224.2244 & 233.7525 \\
\hline
\end{tabular}

Fonte: Elaborado pelos autores com base nos dados do CEPALSTAT (2018).

A Tabela anterior fez a aplicação do teste para conhecermos os valores dos critérios de informação AIC (Akaike's Information Criterion) e BIC (Bayesian Information Criterion). O Modelo4 ou ARMA $(1,0,1)$ / ARMA4 (1, 1, 0, 4) apresentou AIC e BIC menores que os demais modelos, indicando que o quarto modelo é melhor.

Buscando finalizar o modelo ARIMA/SARIMA de análise de conjuntos de dados de séries temporais, existe a necessidade de verificar se os resíduos seguem um formato de ruído branco: sem memória, homocedásticos e normalmente distribuídos. 
Para verificar se o processo possui memória é necessário solicitar o correlograma dos resíduos. Para pedir o correlograma dos resíduos é preciso criar os resíduos (logo após a estimação do modelo). Os gráficos 5 e 6 apresentam o FAC e o FACP dos resíduos do modelo.

\section{Gráficos 5 e 6 - FAC e FACP dos residuos do modelo}
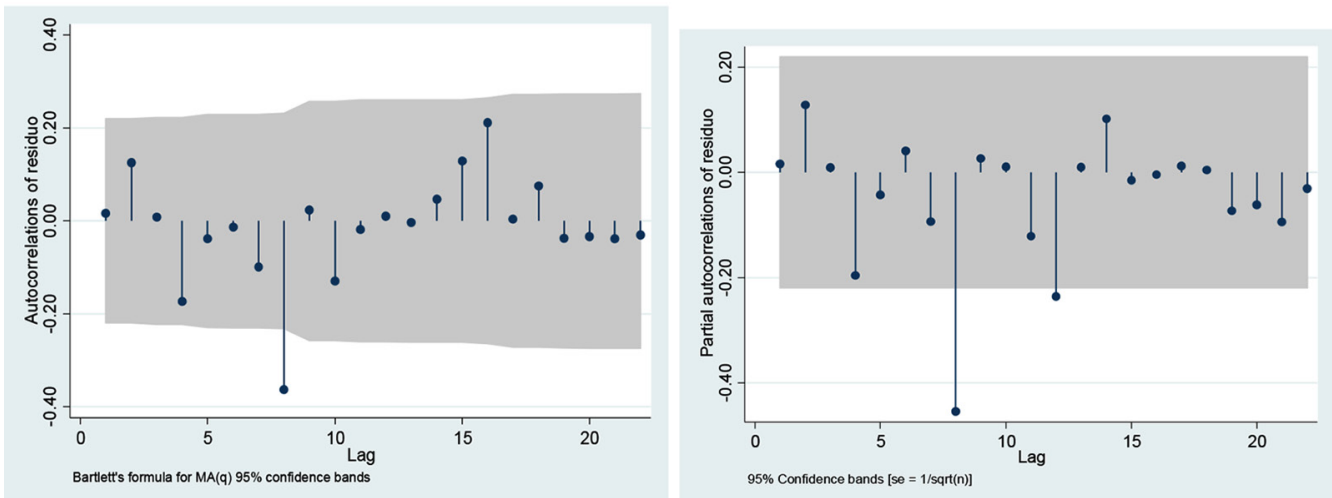

Fonte: Elaborada pelos autores com base nos dados do CEPALSTAT (2018).

Conforme a Figura anterior, as duas estimações, FAC e FACP dos resíduos do modelo apresentaram resultados satisfatórios, porém possuem memória. Adicionalmente aos testes FAC e FACP, apresentamos o teste de Ljung-Box. A Tabela 5 apresenta o correlograma contendo os resultados do teste Ljung-Box. 
Tabela 5 - Teste Ljung-Box

\begin{tabular}{|c|c|c|c|c|c|c|}
\hline LAG & $\mathrm{AC}$ & PAC & $\mathrm{Q}$ & Prob $>Q$ & [Autocorrelation] & [Partial \\
\hline 1 & 0.0160 & 0.0162 & .02117 & 0.8843 & & \\
\hline 2 & 0.1257 & 0.1284 & 1.3492 & 0.5094 & - & \\
\hline 3 & 0.0086 & 0.0091 & 1.3555 & 0.7160 & & \\
\hline 4 & -0.1732 & -0.1958 & 3.9448 & 0.4135 & -1 & - \\
\hline 5 & -0.0382 & -0.0427 & 4.0721 & 0.5391 & & \\
\hline 6 & -0.0133 & 0.0409 & 4.0879 & 0.6648 & & \\
\hline 7 & -0.0986 & -0.0928 & 4.9624 & 0.6646 & & \\
\hline 8 & -0.3632 & -0.4541 & 16.98 & 0.0303 & 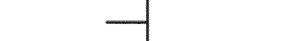 & 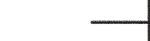 \\
\hline 9 & 0.0232 & 0.0268 & 17.029 & 0.0483 & & \\
\hline 10 & -0.1299 & 0.0104 & 18.61 & 0.0455 & -1 & \\
\hline 11 & -0.0186 & -0.1208 & 18.643 & 0.0678 & & \\
\hline 12 & 0.0104 & -0.2358 & 18.653 & 0.0972 & & - \\
\hline 13 & -0.0031 & 0.0100 & 18.654 & 0.1342 & & \\
\hline 14 & 0.0466 & 0.1018 & 18.87 & 0.1700 & & \\
\hline 15 & 0.1296 & -0.0146 & 20.565 & 0.1513 & - & \\
\hline 16 & 0.2116 & -0.0043 & 25.153 & 0.0672 & - & \\
\hline 17 & 0.0040 & 0.0125 & 25.154 & 0.0913 & & \\
\hline 18 & 0.0759 & 0.0048 & 25.764 & 0.1053 & & \\
\hline 19 & -0.0370 & -0.0732 & 25.911 & 0.1327 & & \\
\hline 20 & -0.0337 & -0.0613 & 26.035 & 0.1646 & & \\
\hline 21 & -0.0381 & -0.0941 & 26.197 & 0.1990 & & \\
\hline 22 & -0.0300 & -0.0307 & 26.299 & 0.2391 & & \\
\hline
\end{tabular}

Fonte: Elaborada pelos autores com base nos dados do CEPALSTAT (2018).

O Quadro anterior contendo o teste Ljung-Box, apresenta o correlograma contendo os ruídos existentes no conjunto de dados de séries temporais utilizado no estudo. Apesar dos resultados serem satisfatórios, faz-se necessário verificar se estes resíduos possuem memória ou ruído branco. Para tal, foi realizado o teste de White-Noise e o teste de Portmanteau. O primeiro pode ser obtido através do periodograma cumulativo. O Gráfico 7 apresenta o periodograma cumulativo do Teste de White-Noise. 
BEIRÃO, É. S.; GONÇALVES, M. E.; SILVA NETO, D. R. Desemprego no Brasil...

\section{Gráfico 7 - Teste de White-Noise}

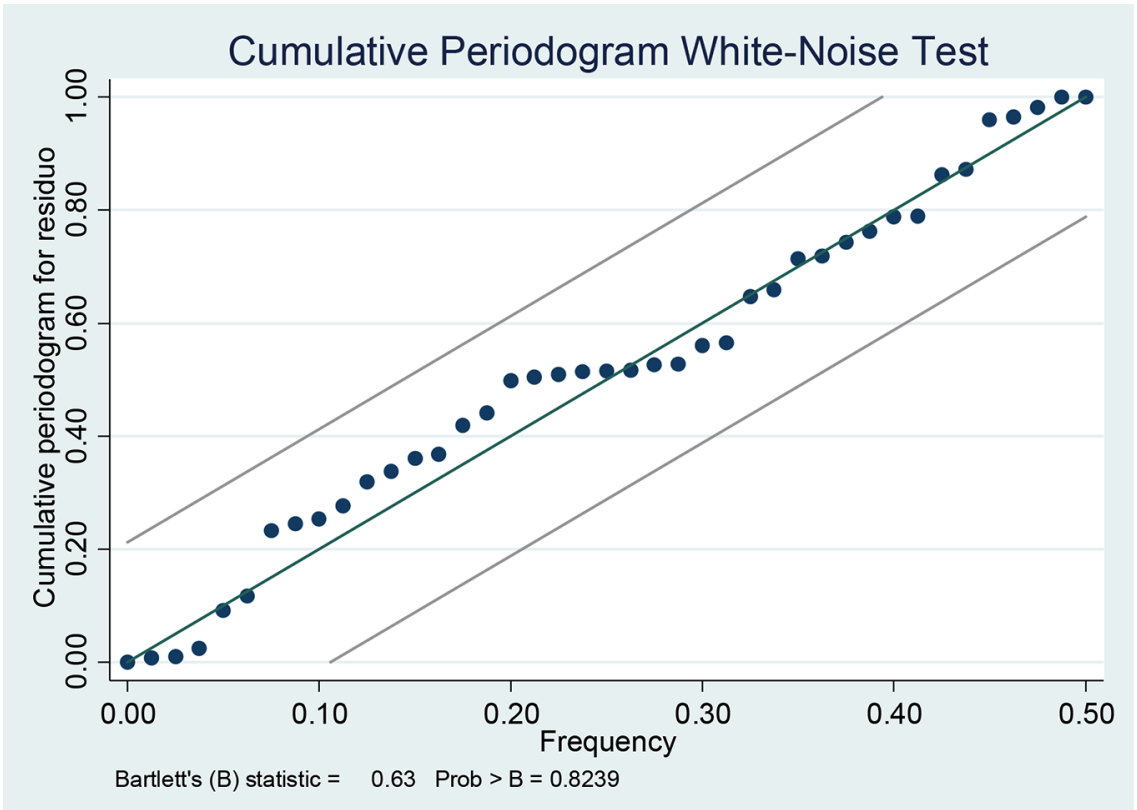

Fonte: Elaborado pelos autores com base nos dados do CEPALSTAT (2018).

Através da aplicação dos resultados dos testes de White-Noise, não se rejeita a hipótese que os resíduos são ruído branco, ou seja, os resíduos do modelo possuem ruído branco. O teste de Portemanteau apresentou valor 34,63, corroborando com resultado do teste White-Noite, ou seja, a hipótese nula não foi rejeitada e os resíduos do modelo possuem ruído branco.

Outro teste que pode ser realizado a respeito dos resíduos do modelo é o Dickey-Fuller Aumentado (ADF), buscando verificar a estacionariedade dos dados. A Tabela 7 apresenta do teste ADF dos resíduos do modelo.

Tabela 7 - Teste ADF dos residuos

\begin{tabular}{l|c|c|c|c}
\hline Defasagens (LAGs) & $\begin{array}{c}\text { Estatistica } \\
\mathbf{t}\end{array}$ & P-valor & $\begin{array}{c}\text { Valor Critico } \\
\mathbf{( 5 \% )}\end{array}$ & $\begin{array}{c}\text { Valor Critico } \\
\mathbf{( 1 0 \% )}\end{array}$ \\
\hline 0 & -8.625 & 0.0000 & -1.950 & -1.610 \\
0 & -8.618 & 0.0000 & -3.471 & -3.163 \\
0 & -8.572 & 0.0000 & -1.665 & -1.293 \\
\hline
\end{tabular}

Fonte: Elaborada pelos autores com base nos dados do CEPALSTAT (2018). 
Conforme os resultados do teste ADF apresentados na Tabela 7, há estacionariedade nos resíduos do Modelo4. Adicionalmente a este teste, foi realizado outro teste, o de heteroscedasticidade para os resíduos do modelo. A Tabela 8 apresenta o teste de heteroscedasticidade dos resíduos do modelo.

Tabela 8 - Teste ADF dos resíduos

\begin{tabular}{l|l|l|l}
\hline Defasagens & $\chi^{\mathbf{2}=\mathbf{c h i 2}}$ & Defasagens & Prob $>\chi^{2}=\mathbf{c h i 2}$ \\
\hline 1 & 0.063 & 1 & 0.8017 \\
2 & 0.064 & 2 & 0.9687 \\
3 & 0.097 & 3 & 0.9921 \\
4 & 0.808 & 4 & 0.9374 \\
5 & 0.859 & 5 & 0.9731 \\
6 & 0.918 & 6 & 0.9885 \\
7 & 0.954 & 7 & 0.9955 \\
8 & 4.129 & 8 & 0.8453 \\
9 & 4.264 & 9 & 0.8932 \\
10 & 4.213 & 10 & 0.9373 \\
11 & 4.406 & 11 & 0.9565 \\
12 & 4.585 & 12 & 0.9704 \\
13 & 4.557 & 13 & 0.9837 \\
14 & 4.589 & 14 & 0.9908 \\
15 & 4.526 & 15 & 0.9954 \\
16 & 4.693 & 16 & 0.9971 \\
17 & 4.631 & 17 & 0.9986 \\
18 & 4.800 & 18 & 0.9991 \\
19 & 4.820 & 19 & 0.9996 \\
20 & 4.899 & 20 & 0.9998 \\
21 & 4.914 & 21 & 0.9999 \\
22 & 4.881 & 22 & 1.0000 \\
\hline
\end{tabular}

Fonte: Elaborada pelos autores com base nos dados do CEPALSTAT (2018).

De acordo com o p-valor do teste qui-quadrado, não se rejeita a hipótese nula de homoscedasticidade para as 22 primeiras defasagens. Como os resultados estão livres de memória e são homoscedasticos, o Modelo4 pode ser utilizado para a previsão.

Tendo sido realizada tal etapa, partimos para a previsão. Feita a estimação, os valores previstos serão em relação à variável em nível utilizada no modelo ARIMA/SARIMA serão calculados para o período da amostra, que vai do primeiro trimestre do ano de 1995 ao primeiro trimestre do ano 
BEIRÃO, É. S.; GONÇALVES, M. E.; SILVA NETO, D. R. Desemprego no Brasil...

de 2016. O Gráfico 8 apresenta a relação entre os valores realizados e previstos dentro da série.

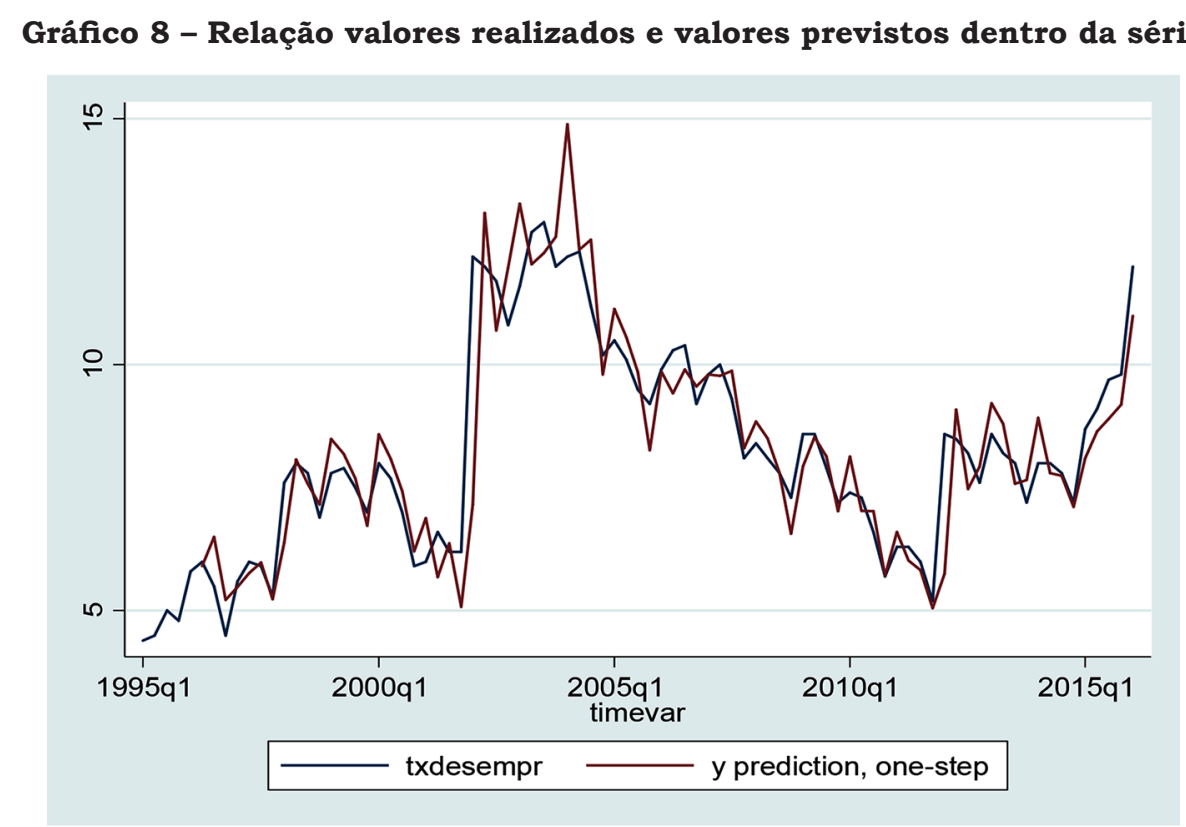

Fonte: Elaborado pelos autores com base nos dados do CEPALSTAT (2018).

O Gráfico 8 comprova que os resultados previstos não acompanham totalmente os valores realizados, sendo necessário fazer a previsão fora da série com o intuito de prever a tendência da taxa de desemprego do Brasil para os próximos 14 semestres, ou seja, até o último semestre do ano 2019. O Gráfico 9 apresenta a previsão fora da série da taxa de desemprego do Brasil. 


\section{Gráfico 9 - Previsão fora da série}

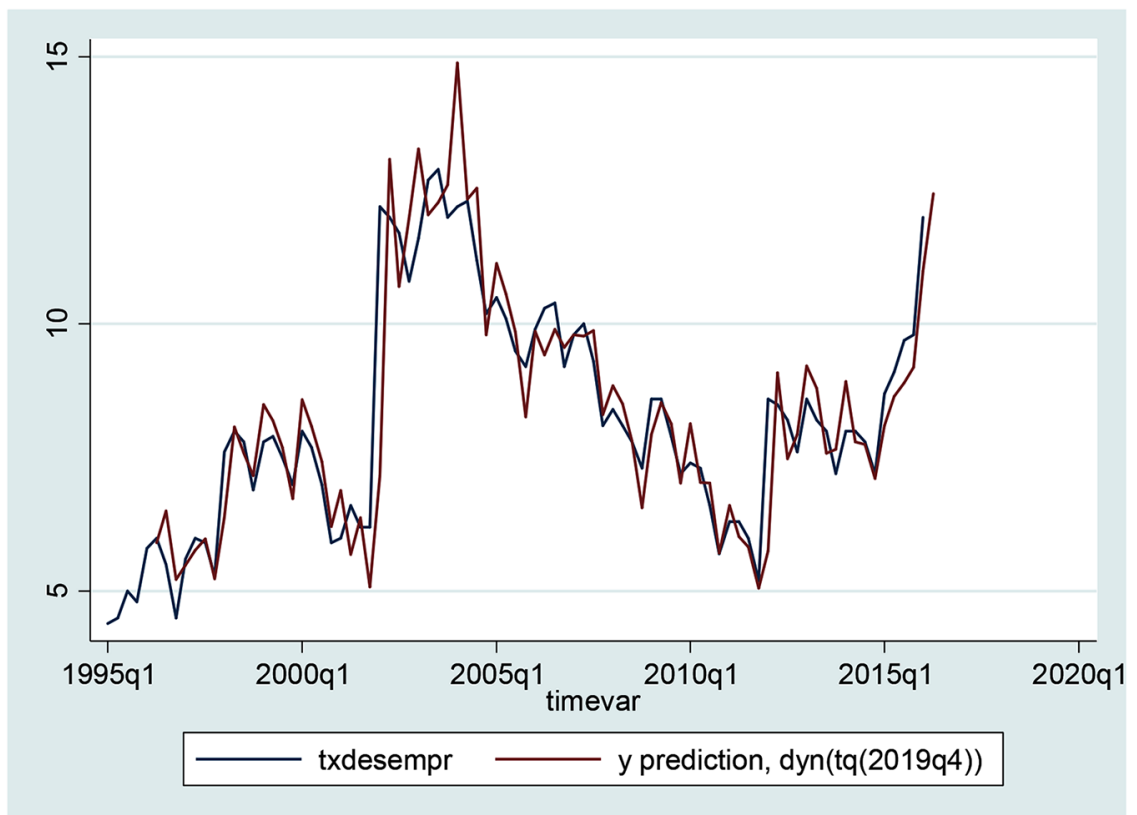

Fonte: Elaborado pelos autores com base nos dados do CEPALSTAT (2018).

A previsão fora da série indica que pode haver a elevação da taxa trimestral de desemprego do Brasil até o último trimestre de 2019. O que se observa no Brasil é que até o ano de 2015, o país experimentou taxas mais baixas de desocupados (desempregados). Outro aspecto que pode ser acrescentado é que os resultados encontrados vão de encontro com as previsões feitas por economistas, o que corrobora com a análise, indicando assim que estas previsões tem se cumprido e o desemprego se elevou nos trimestres subsequentes.

O desemprego também tende a crescer ainda mais em decorrência das políticas fiscais, econômicas e sociais que têm sido adotadas pelos atuais governantes, de restrição orçamentária, contenção de gastos públicos sociais e corte/suspensão de direitos sociais e trabalhistas adquiridos no decorrer do tempo. O Brasil vive os resultados da reforma da Previdência Social que retirou do trabalhador direitos e pode provocar a curto, médio ou longo prazo a transição deste para o mercado informal ou para a inatividade, como evidenciou Ferreira (2016).

Pochmann (2015) afirmou que o Brasil está enfrentando uma forte 
BEIRÃO, É. S.; GONÇALVES, M. E.; SILVA NETO, D. R. Desemprego no Brasil...

tendência do crescimento do desemprego neste contexto recessivo. O mesmo, a partir de seus estudos, chegou à conclusão que há uma discrepância entre demanda por trabalhadores e a oferta de postos de trabalho. Há também aumento acirramento no âmbito do mercado de trabalho devido ao fato dos adultos estarem a procura de emprego e os jovens estarem tentando ingressarem no mesmo.

Outro aspecto que pode ter contribuído fortemente para o aumente da taxa de desemprego a ser considerado é a Reforma Trabalhista de 2017 que através da Lei $\mathrm{N}^{\circ} 13.467$, de 13 de julho de 2017 trouxe mudanças significativas na Consolidação das Leis Trabalhistas (CLT). Apesar de ter sido realizada com o propósito de combater o desemprego e a crise econômica de 2014, as flexibilizações dessa Reforma acabaram por provocar o aumento do desemprego e da informalidade no país.

Os autores que estudaram a evolução e a composição (estrutura) do desemprego chegaram à conclusão que a escolaridade é um dos determinantes mais decisivos para o aumento ou diminuição da taxa de desemprego (BIVAR; 1993; CORSEUIL, 1994; CORSEUIL, REIS E URANI; 1996; BARROS, CAMARGO E MENDONÇA, 1997; FLORI, 2003; POCHMANN, 2015; FERREIRA, 2016).

\section{Considerações Finais}

Este estudo teve como objetivo prever a da taxa de desemprego do Brasil através da análise empírica baseada em dados de séries temporais. Para analisar a questão problema supracitada foi utilizada uma análise de previsão em séries temporais, realizada por meio da utilização da metodologia Box-Jenkins.

Os resultados são condizentes com boa parte da literatura e apontam para o fato de que a taxa de desemprego tem se elevado no Brasil e tendem a se elevar ainda mais nos próximos 14 trimestres. A série ou conjunto de dados de series temporais da taxa de desemprego trimestral do Brasil entre o primeiro semestre do ano de 1995 e o primeiro semestre de 2016, apresentou-se estacionária, pois ela se desenvolve no tempo aleatoriamente ao redor da média, refletindo um tipo de equilíbrio na variável utilizada. 
O estudo abre precedentes para a realização de pesquisas mais avançadas acerca dos determinantes do desemprego no Brasil e na investigação de outros problemas sociais que permeiam a sociedade brasileira, estes provocados pelo crescimento do desemprego, como é o caso da criminalidade, violência, analfabetismo, saúde pública, desigualdade sociais e econômicas.

Outro aspecto que não foi evidenciado no âmbito deste estudo que têm provocado a elevação das taxas de desemprego é a pandemia do COVID-19 que teve seu início em meados do mês de março do ano 2020 no Brasil. Vários setores da economia têm sofrido com o adoecimento dos trabalhadores, mortes e perda de postos de trabalho. Portanto, outro encaminhamento para estudos futuros é verificar o impacto desta pandemia na taxa de desemprego no Brasil.

\section{Referências}

BARROS, R. P.; CAMARGO, J. M.; MENDONÇA, R. S. P. A estrutura do desemprego no Brasil. Rio de Janeiro: IPEA, 1997. (Texto para discussão, n. 478).

BECKER, M. H. Modelos para previsão em séries temporais: uma aplicação para a taxa de desemprego na Região Metropolitana de Porto Alegre. 2010. 46 f. Monografia (Bacharel em Estatística) Universidade Federal do Rio Grande do Sul, Porto Alegre, 2010.

BIAVASCHI, C. et al. Youth unemployment and vocational training. Discussion paper, n. 6. 890, 2012.

BIVAR, W. Aspectos da estrutura do desemprego no Brasil: composição por sexo e duração. Rio de Janeiro: BNDES, XV Prêmio BNDES, 1993 (Dissertações de Mestrado).

BLANCHARD, O. European Unemployment: the evolution of facts and ideas. Cambridge: Massachusetts Institute of Technology, nov. 2005.

BOX, G. P. E.; JENKINS, G. M. Times series analysis: forecasting and control. ed. rev. Holden Day, São Francisco: Holden, 1978.

BRASIL. Lei $\mathrm{N}^{\circ}$ 13.467, de 13 de julho de 2017. Altera a Consolidação das Leis do Trabalho (CLT), aprovada pelo Decreto-Lei $\mathrm{N}^{\circ} 5.452$, de $1^{\circ}$ de maio de 1943, e as Leis $\mathrm{N}^{\circ} 6.019$, de 3 de janeiro de 1974, 8.036, de 11 de maio de 1990, e 8.212, de 24 de julho de 1991, a fim de adequar a legislação às novas relações de trabalho. Brasília: Diário Oficial da União, 2017. Dis- 
BEIRÃO, É. S.; GONÇALVES, M. E.; SILVA NETO, D. R. Desemprego no Brasil...

ponível em: <http://www.planalto.gov.br/ccivil_03/_ato2015-2018/2017/ lei/113467.htm>. Acesso em: 09 de novembro de 2021.

BUENO, R. L. S. Econometria de Séries Temporais. 2.ed. rev. e atual. São Paulo: Cengage Learning, 2012

COMISSÃO ECONÔMICA PARA A AMÉRICA LATINA E O CARIBE. Bases de Datos y Publicaciones Estadísticas. Santiago, Chile: CEPAL, 2018. Disponível em: <https://statistics.cepal.org/portal/cepalstat/index.html?lan$\mathrm{g}=\mathrm{es}>$. Acesso em: 9 nov. 2021.

CORSEUIL, C. H. L. Desemprego: aspectos teóricos e o caso brasileiro. Série Seminários, 4/94. Rio de Janeiro: IPEA, abr. 1994.

CORSEUIL, C. H. L.; REIS, C.; URANI, A. Determinantes da estrutura do desemprego no Brasil: 1986/95. In: $23^{\circ}$ ENCONTRO NACIONAL DE ECONOMIA. Águas de Lindóia: ANPEC, 1996.

CORSEUIL, C. H. L.; POLOPONSKY, K.; FRANCA, M. A. P. Uma interpretação para a forte aceleração da taxa de desemprego entre os jovens. Nota Técnica IPEA, n. 64, abril. 2018.

COSTA, D. P. C. Uma análise descritiva do índice de desemprego no Brasil. 2015. 45 f. Dissertação (Mestrado em Finanças e Economia). Escola de Economia de São Paulo, Fundação Getúlio Vargas. São Paulo, 2015.

DICKEY, D. A.; FULLER, W. A. Distribution of the estimators for autoregressive time series with a unit root. Journal of the Statistical Association, v.74, p. 427-431, 1979.

FERREIRA, E. F. Desemprego e Inatividade em Regiões Metropolitanas Brasileiras: por faixa etária, escolaridade, gênero e cor, em 2014. 2016. 58 f. Monografia (Curso de Ciências Econômicas) Centro de Estudos Sociais Aplicados, Universidade Estadual de Londrina, Londrina, 2016.

FLORI, P. M. Desemprego de jovens: um estudo sobre a dinâmica do mercado de trabalho juvenil brasileiro. 2003. 77 f. Dissertação (Mestrado em Economia) - Universidade de São Paulo, São Paulo, 2003.

GOUVEIA, J. M. A.; MONSUETO, S. E. Introdução à Séries Temporais e Modelagem ARIMA no Stata. Goiânia: FACE/UFG, 2016.

GUJARATI, D. N.; PORTER, D. C. Econometria básica. 5. ed. Porto Alegre: AMGH, 2011.

IANNI, O. Teorias da globalização. 4. ed. Rio de Janeiro: Civilização Brasileira, 1997. 
KLIKSBERG, B. Falácias e Mito do Desenvolvimento Social. São Paulo: Cortez Editora, 2001.

LAYARD, R.; NICKELL, S.; JACKMAN, R. Unemployment: Macroeconomic Performance and the Labour Market. 2. ed. New York: Oxford University Press Inc., 2009.

MAIA, K. Progresso tecnológico, qualificação da mão de obra e desemprego. 2001. 184 f. Tese (Doutorado em Economia) - Universidade de Brasília, Brasília, 2001.

MARIM, W. C. Absorção de mão-de-obra e modernização da agricultura no Brasil. R. Adm. Emp., Rio de Janeiro, 16 (5): 33-47, set. /out. 1976.

MOCHON, F.; TROSTER, L. R. Introdução à economia. São Paulo: Makron Books, 1994.

NOCCIOLI, V. M. Desemprego: a instituição política de uma questão social. Rev. Mediações, Londrina, v. 4, n. 2, p. 58-65, jul. /dez. 1999.

PINDICK, R. S.; RUNBINFIELD, D. L. Econometria: modelos e previsões. Rio de Janeiro: Elsevier, 2004.

PINHEIRO, L. I. F.; DIAS, G. O. Questão social: um conceito revisitado. Contribuciones a las Ciencias Sociales, febrero 2009.

POCHMANN, M. Ajuste econômico e desemprego recente no Brasil metropolitano. Estudos Avançados, 29 (85), 2015.

REINERT, J. N. Desemprego: causas, consequências e possiveis soluções. Revista de Ciências da Administração, v. 3, n. 5, p. 45-48, 2001.

ROCHA, S. Metropolização da pobreza: uma análise nucleoperiférica. Perspectivas da Economia Brasileira. Rio de Janeiro: IPEA, v.2, p. 527- 539, 1993.

SENA, A. G. Trabalho e desemprego no contexto contemporâneo: algumas reflexões. Rev. Trib. Reg. Trab. $3^{a}$ Reg. - Belo Horizonte, 29 (59): 99-128, Jan./Jun. 1999.

WOOD, A. North-South Trade, Employment and Inequality: Changing Fortunes in a Skill Driven World. New York. Oxford UK, 1995. 